\title{
The UK summer heatwave of 2018 and public concern over energy security
}

\author{
Shaun Larcom ${ }^{1 *}$, Po-Wen She ${ }^{1,2}$, Terry van Gevelt ${ }^{3}$ \\ ${ }^{1}$ Department of Land Economy, University of Cambridge, United Kingdom \\ ${ }^{2}$ National Institute of Economic and Social Research, United Kingdom \\ ${ }^{3}$ Department of Politics and Public Administration, University of Hong Kong, Hong Kong SAR \\ *Corresponding author (stl25@cam.ac.uk)
}

The UK summer heatwave of 2018 led to changes in consumer behaviour, including large increases in electricity demand due to increased use and intensity of refrigeration and aircondition devices $(1,2)$. While the UK experienced its equal hottest summer on record, the extreme temperatures were concentrated in the south and east of England (3). We exploit the regional variation to test for the effect of experiencing extreme temperatures on resource security perceptions and related pro-environmental behaviour. We analyse data from 2,189 individuals across the UK over a seven-day period and employ a difference-in-differences type estimation to compare individuals' responses in regions subjected to extreme temperatures with individuals' responses in regions that were not subjected to extreme temperatures (4). We show evidence that suggests exposure to extreme temperatures had a large and statistically significant effect on perceptions of energy security but not on stated pro-environmental behaviour. We find less evidence that extreme temperatures had an effect on perceptions of food and water security.

A changing climate and the increased frequency of weather extremes is exacerbating the stresses on natural resource availability $(5,6)$. To meet these challenges, we need to understand the degree and extent to which exposure to extreme weather affects individuals' perceptions of resource security and related consumption behaviour. This is needed for two reasons. The first relates to measuring the potential for autonomous adaptation; where exposure to extreme whether events could change individual perceptions and consequently behaviour. The second, related reason, concerns better understanding the relationship between experience of extreme weather events and the public acceptability of environmental taxes and policies. These often continue to face widespread public opposition despite increased acceptance of anthropocentric climate change.

In the context of incomplete information, extreme weather events may change perceptions and/or behaviour through two potential channels. The first channel is through a Bayesian updating process, whereby extreme weather events can provide tangible evidence of a changing climate that is likely to affect resource use and availability (7). The second channel is via a salience effect, whereby actually experiencing extreme weather events may make climate-related considerations more prominent (7-9). We can expect Bayesian updating to lead to more stable and lasting perceptions, whereas salience effects are likely to generate more ephemeral perceptions that are heavily influenced by contemporaneous (or recent) temperatures (7). We build on a growing literature examining how extreme weather events can affect environmental risk perceptions (10-15) by tracking perceptions and stated behaviour on a daily basis and matching it with daily localised temperature data using a difference-in-differences approach. Such a set-up enables us to aim to measure the effects of heat exposure itself and to control for possible UK-wide variations during this period (e.g. London-based nationwide media coverage). This is important because, as at the time, the heatwave received widespread media coverage. 
We define a region to have experienced extreme temperatures when the maximum daily temperature is equal to or exceeds 29 degrees Celsius. This is an established figure for measuring extreme temperatures $(16,17)$. Six of the 11 regions in the study experienced extreme temperatures during the survey period, with all six regions first experiencing temperatures of at least 29 degrees Celsius on 23 July (see Supplementary Figures 1 and 2). We use this regional variation to generate treatment and control groups.

Figure 1 provides context for the 2018 heatwave and our sample period of 18 to 25 July by plotting the daily average maximum temperature for June and July for our treatment and control regions. Both groups began to experience warmer weather from late June. During our sample period, while there are fluctuations, both groups had relatively mild temperature to begin with. While the temperature stayed relatively mild in our control regions (with a maximum average of 24 degrees) in the sample period, the treatment group experienced much hotter temperatures. It is also noteworthy that while temperatures peaked beyond our sample period (26 July), 23 July seemed to mark a perceptible period of extreme heat, with web searches for the term 'heatwave' peaking on this day for the UK (see Supplementary Figure 3).

Given the marked differences in localised temperatures over our sample period, we are able to test for the effect of being exposed to extreme temperatures; where those individuals who were sampled in the regions that experienced extreme temperatures form the treatment group and those who were sampled in regions that did not experience extreme temperatures form the control group. We then evaluate the difference in mean responses between those sampled before the onset of extreme temperatures with those sampled on or after for both treatment and control groups. We take the difference of these two measures while controlling for demographics, and day and region fixed effects. We also control for environmental preferences and attitudes towards government regulation of the environment (12).

This provides us with our difference-in-differences estimator, Post.Treatment, where the post period is 23 - 25 July and the treatment group are those individuals in regions who experienced temperatures of at least 29 degrees Celsius during our sample period. In employing this method, we acknowledge that the control group also experienced an unusually warm summer, albeit not as extreme as the treatment group.

Table 1 shows descriptive statistics generated from a survey of individuals across the UK in aggregate and by group. The number of survey respondents per day and pre- and post-treatment are provided in Supplementary Tables 2 and 3. There are approximately one-third more individuals within the treatment regions than in the non-treatment regions. We provide a balance test between our treatment and control groups in terms of demographic characteristics and other control variables. The two groups are broadly similar, however the treatment group is notably younger (see Supplementary Table 4). Importantly, we control for age and other observable characteristics in our econometric estimation. We conducted a number of further robustness tests, including a parallel trends test, estimations using wild bootstrapped standard errors and an alternative specification of extreme temperature (see Methods).

Respondents were asked to report their level of agreement with a set of three statements on perceptions of water, energy, and food-security (measured by future shortages) and a set of three 
statements concerning water, energy and food consumption behaviour along a 100-point scale. A value of 0 indicated that the respondent strongly disagreed with the statement. A value of 50 indicated that the respondent neither agreed nor disagreed. A value of 100 indicated that the respondent strongly agreed with the statement. In terms of the aggregate data, respondents were generally concerned with water, energy and food-security with average scores ranging from 53.85 to 62.54 . Respondents were similarly concerned with stated pro-environmental behaviour, with average scores ranging from 58.83 to 63.75 .

Tables 2 and 3 report our main results using time and regional fixed effects and clustered standard errors for perceptions of energy security and stated energy consumption (proenvironmental) behaviour. Corresponding tables for water and food are presented in Supplementary Tables 5-8). For both Tables 2 and 3, column (1) does not include any control variables and does not include region and time fixed effects. Column (2) includes region and time fixed effects. Column (3) includes a range of demographic controls: age, income, gender and education. Column (4) includes demographic controls, as well as our variables representing environmental preferences (measured by stated pro-environmental behaviour) and stance toward environmental regulation (measured by support for a tax on packaging).

Starting with Table 2, the key variable of interest is our difference-in-differences estimator (Post.Treatment) and its coefficient that aims to capture the treatment effect. That is, the impact of extreme temperatures by measuring the change in the perceptions of energy security of individuals who experienced extreme temperatures relative to the control group of individuals who did not experience extreme temperatures over the sample period. In our preferred specification (column 4), our coefficient is positive (5.147 percentage points) and significant at the $5 \%$ level $(\mathrm{p}=0.023)$. This suggests that individuals who were subjected to extreme temperatures were more likely to perceive future energy shortages. As shown in Supplementary Tables 9-14, similar results were obtained when using wild cluster bootstrapped standard errors and an alternative measure of extreme temperatures. We find less evidence for the impact of extreme temperatures on perceptions of water and food security (4.018 percentage points and 4.673 percentage points, respectively) with our difference-in-differences estimator only being statistically significant at the $10 \%$ level ( $p=0.096$ and $p=0.091$, respectively) when using our alternative measure of extreme temperatures (see Supplementary Tables 13 and 14).

Table 3 reports the effect of extreme temperatures on stated energy consumption (proenvironmental) behaviour. While our coefficients are positive suggesting that individuals who were subject to extreme temperatures were more likely to consider environmental impacts in their energy consumption decisions, our coefficient (2.73 percentage points) for our preferred specification (column 4 ) is not statistically significant $(\mathrm{p}=0.158)$. We find similar results for stated water and food consumption behaviour (see Supplementary Tables 7 and 8). As shown in Supplementary Tables 15-20, similar results were obtained when using wild cluster bootstrapped standard errors and an alternative measure of extreme temperatures

By matching daily temperature data with individual-level survey data and exploiting regional variations in the recent UK summer heatwave, we have aimed to measure the effect of localised exposure to extreme temperatures on resource security perceptions and stated pro-environmental 
behaviour by way of a natural experiment. We find evidence that suggests exposure to extreme temperatures has a large and statistically significant effect on perceptions of energy security. To contextualise our results, we know that the heatwave led to a spike in electricity consumption and highlighted the long-term viability of the UK's fuel mix, which is still heavily reliant on fossil fuels (18). We found less evidence that exposure to extreme temperatures led to changes in perceptions of water and food security despite relatively low levels of rainfall and several highprofile food shortages occurring during this period (1-3). This may be partly explained by the fact that temperature and precipitation are only partially correlated (19), that the UK imports a large proportion (approximately half) of its food (20) and that climate change is predicted to have an ambiguous effect on UK food production (21). Additionally, there is evidence suggesting that individuals in the UK associate energy-related issues with climate change more than they do water- or food-related issues $(22,23)$.

While we are unable to formally test the channel through which perceptions of energy security have changed, we provide some evidence suggesting that it is likely due to salience effects (7). We do this by re-estimating our difference-in-differences estimation, this time using two waves of respondent data. Our second wave of data were collected during 3-14 December 2018. If perceptions changed through a process of Bayesian updating, we would expect the effect of the summer heatwave on perceptions to be relatively stable over time. If perceptions changed through salience effects, we would expect no systematic difference between the effect of the summer heatwave on perceptions of our treatment and control groups in the second wave given the lack of climate extremes after the summer heatwave (see Supplementary Figures 4 and 5). As shown in Table 4, our difference-in-differences estimator is now close to zero (-0.165 percentage points) and non-significant $(\mathrm{p}=0.913)$. This suggests that the UK heatwave may have affected preferences through the salience of extreme temperatures rather than through a Bayesian process of updating.

Despite finding evidence that suggests exposure to extreme temperatures during the UK summer heatwave did change people's immediate perceptions of energy security, it did not necessary seem to last or lead to a change in people's intentions to change their resource consumption behaviour. While it is possible that exposure to multiple extreme weather events as opposed to a single extreme weather event may lead to stable changes in perception and behaviour, our findings provide an important insight for policy makers as they may highlight the limitations of relying on individuals to autonomously adapt to climate change despite being exposed to a highly salient extreme weather event. Instead, it is likely that governments (and other organisations) will need to play a coordinating role and provide individuals with the incentives needed to move closer toward sustainable resource management.

The second key insight from our analysis builds on our first. In doing so, it contributes to the climate change attribution and public policy literature, both in terms of methodology and scope $(24,25)$. Despite the need for increased government action to align the incentives of individuals with society to limit climate change, we know that such measures are difficult to introduce, and when they are, they often face largescale public disapproval. The gilet jaunes movement (multifaceted as it is) is the latest in a long line of popular anti-environmental tax protests, often 
despite increasing public acceptance of anthropogenic climate change (26). Our results suggest that experiencing extreme temperatures may lead to a marked and immediate increase in concern

for energy security. This suggests that the salience effects generated by a heatwave may create a window of opportunity for policies focusing on energy security in the context of climate change to be enacted.

\section{References}

1. BBC, "UK weather: What are the effects of a heatwave?” https://www.bbc.co.uk/news/uk-44680164. (2018).

2. Reuters, "Heatwave boosts British power demand.” https://www.reuters.com/article/usbritain-weather-electricity/heatwave-boosts-british-power-demand-reportidUSKBN1KH1MP. (2018).

3. UK Met Office, "Was summer 2018 the hottest on record?” https://www.metoffice.gov.uk/news/releases/2018/end-of-summer-stats. (2018).

4. M. Dell, B. Jones, B. Olken, What do we learn from the weather? The new climateeconomy literature. Journal of Economic Literature 52, 740-798 (2014).

5. M. Bazilian, H. Rogner, M. Howells, S. Hermann, D. Arent, D. Gielen, P. Stedutor, Considering the energy, water and food nexus: towards an integrated modelling approach. Energy Policy 39, 7896-7906 (2011).

6. M. Howells, S. Hermann, M. Welsch, M. Bazilian, R. Segerstrom, T. Alfstad, D. Gielen, H. Rogner, G. Fischer, H. van Velthuizen, D. Wiberg, C. Young, R. Roerhl, A. Mueller, P. Steduto, I. Ramma, Integrated analysis of climate change, land-use, energy and water strategies. Nature Climate Change 3, 621-626 (2013).

7. T. Deryugina, How do people update? The effects of local weather fluctuations on beliefs about global warming. Climatic Change 118, 397-416 (2013).

8. P. Bordalo, N. Gennaioli, A. Shleifer, Salience theory of choice under risk. The Quarterly Journal of Economics 127, 1243-1285 (2012).

9. P. Bordalo, N. Gennaioli, A. Shleifer, Salience and consumer choice. Journal of Political Economy 121, 803-843 (2013).

10. J. Hansen, M. Sato, R. Ruedy, Perception of climate change. Proceedings of the National Academy of Sciences 109, E2415-E2423 (2012).

11. A. Spence, W. Poortinga, C. Butler, N. Pidgeon, Perceptions of climate change and willingness to save energy related to flood experience. Nature Climate Change 1, 46 (2011). 12. T. Lee, E. Markowitz, P. Howe, C. Ko, A. Leiserowitz, Predictors of public climate change awareness and risk perception around the world. Nature Climate Change 5, 1014 (2015).

13. C. Zanocco, H. Boudet, R. Nilson, H. Satein, H. Whitley, J. Flora, Place, proximity and perceived harm: extreme weather events and views about climate change. Climatic Change 149, 349-365 (2018).

14. P. Howe, Perceptions of seasonal weather are linked to beliefs about global climate change: evidence from Norway. Climatic Change 148, 467-480 (2018). 
15. C. Demski, S. Capstick, N. Pidgeon, R. Sposato, A. Spence, Experiences of extreme weather affects climate change mitigation and adaptation responses. Climatic Change 140, 149-164 (2017).

16. M. Burke, K. Emerick, Adaptation to climate change: evidence from US

agriculture. American Economic Journal: Economic Policy 8, 106-40 (2016).

17. M. Burke, S. Hsiang, E. Miguel, Global non-linear effect of temperature on economic production. Nature 527, 235 (2015).

18. S. Pye, F. Li, J. Price, B. Fais, Achieving net-zero emissions through the reframing of UK national targets in the post-Paris Agreement era. Nature Energy 2, 17024 (2017).

19. IPCC, "The physical science basis: consistency and relationships between temperature and precipitation.” https://www.ipcc.ch/publications_and_data/ar4/wg1/en/ch3s3-3-

5.html (2017).

20. Defra, "Food statistics pocketbook.” https://www.gov.uk/government/publications/foodstatistics-pocketbook-2017/food-statistics-in-your-pocket-2017-global-and-uksupply (2017).

21. Committee on Climate Change, "UK climate change risk assessment 2017: Synthesis report.” https://www.thecc.org.uk/wp-content/uploads/2016/07/UK-CCRA-2017-SynthesisReport-Committee-on-Climate-Change.pdf (2017).

22. L. Whitmarsh, What's in a name? Commonalities and differences in public understanding of "climate change” and "global warming." Public Understanding of Science 18: 401-420 (2009).

23. T. Partridge, M. Thomas, B. Harthorn, N. Pidgeon, A. Hasell, L. Stevenson, C. Enders, Seeing futures now: Emergent US and UK views on shale development, climate change and energy systems. Global Environmental Change 42, 1-12 (2017).

24. Q. Schiermeier, Droughts, heatwaves and floods: How to tell when climate change is to blame. Nature 560, 20-22 (2018).

25. A. Ray, L. Hughes, D. Konisky, C. Kaylor, Extreme weather exposure and support for climate change adaptation. Global Environmental Change 46, 104-113 (2017).

26. BBC, "France protests: Will the environment be the true victim of the fuel-tax riots?" http://www.bbc.com/news/world-europe-46439469 (2018).

Correspondence and requests for materials to be addressed to Shaun Larcom (stl25@cam.ac.uk).

Acknowledgments: We are grateful to ResearchNow for their assistance in conducting the survey from their panel of interviewees and to the UK Met Office for providing access to Areal temperature data. We would also like to thank the editor and three anonymous referees for their comments. Funding: This work was supported by the UK Engineering and Physical Sciences Research Council (EPSRC) (grant numbers EP/N005961/1 and EP/N0050600/1) and the Department of Politics and Public Administration at the University of Hong Kong (research account 293010000). Author contributions: All authors contributed equally to the production of this manuscript and order of authorship has been assigned on an alphabetical basis. Data and materials availability: Our data agreement with the UK Met Office precludes the release of raw temperature data. A processed dataset along with replication files are available at http://dx.doi.org/10.6084/m9.figshare.7482614. 


\section{TABLES}

\begin{tabular}{|c|c|c|c|c|c|c|c|c|c|c|c|c|}
\hline & Total & & & & Treatment & & & & Control & & & \\
\hline & Mean & SD & Min & Max & Mean & SD & Min & Max & Mean & SD & Min & Max \\
\hline Perceptions of water security & 62.54 & 25.81 & 0 & 100 & 63.56 & 25.54 & 0 & 100 & 61.04 & 26.13 & 0 & 100 \\
\hline Perceptions of energy security & 61.74 & 25.75 & 0 & 100 & 62.19 & 25.71 & 0 & 100 & 61.07 & 25.81 & 0 & 100 \\
\hline Perceptions of food security & 53.84 & 27.97 & 0 & 100 & 54.53 & 28.04 & 0 & 100 & 52.80 & 27.85 & 0 & 100 \\
\hline Pro-environmental behaviour (water) & 63.75 & 26.37 & 0 & 100 & 64.52 & 25.63 & 0 & 100 & 62.59 & 27.41 & 0 & 100 \\
\hline Pro-environmental behaviour (energy) & 62.95 & 25.88 & 0 & 100 & 63.64 & 25.30 & 0 & 100 & 61.92 & 26.69 & 0 & 100 \\
\hline Pro-environmental behaviour (food) & 58.83 & 26.98 & 0 & 100 & 59.69 & 26.35 & 0 & 100 & 57.55 & 27.87 & 0 & 100 \\
\hline Age & 4.59 & 1.62 & 2 & 7 & 4.50 & 1.62 & 2 & 7 & 4.72 & 1.60 & 2 & 7 \\
\hline Income & 3.88 & 2.28 & 1 & 8 & 3.95 & 2.28 & 1 & 8 & 3.78 & 2.29 & 1 & 8 \\
\hline Gender & 1.50 & 0.50 & 1 & 2 & 1.49 & 0.50 & 1 & 2 & 1.51 & 0.50 & 1 & 2 \\
\hline Education & 2.89 & 1.02 & 1 & 5 & 2.92 & 1.04 & 1 & 5 & 2.85 & 0.98 & 1 & 5 \\
\hline Environmental regulation & $\begin{array}{l}47.96 \\
n=2189\end{array}$ & 32.66 & 0 & 100 & $\begin{array}{l}48.92 \\
n=1310\end{array}$ & 32.47 & 0 & 100 & $\begin{array}{l}46.52 \\
n=879\end{array}$ & 32.90 & 0 & 100 \\
\hline
\end{tabular}

*Note. Descriptive statistics are for data collected during the heatwave (Wave 1). Descriptive statistics for data collected after the heatwave (Wave 2) are presented in Supplementary Table 1.

\section{Table 1. Descriptive statistics}




\begin{tabular}{lcccc}
\hline & $(1)$ & $(2)$ & $(3)$ & $(4)$ \\
\hline Post.Treatment & $2.951^{*}$ & $6.126^{* *}$ & $6.585^{* *}$ & $5.147^{* *}$ \\
Age & $(1.420)$ & $(2.361)$ & $(2.176)$ & $(1.912)$ \\
& & & -0.687 & -0.477 \\
Income & & & $(0.408)$ & $(0.351)$ \\
& & & 0.541 & 0.199 \\
Gender & & $(0.436)$ & $(0.379)$ \\
& & & 1.340 & 0.537 \\
Education & & & $(1.486)$ & $(1.320)$ \\
& & & $4.214^{* * *}$ & $2.054^{* * *}$ \\
Environmental regulation & & & $(0.518)$ & $(0.513)$ \\
& & & $0.0514^{* *}$ \\
Pro-environmental behaviour (Energy) & & & $(0.018)$ \\
& & & & $0.428^{* * *}$ \\
Constant & & & & $(0.016)$ \\
& & & & $23.75^{* * *}$ \\
Region fixed effects & & & & $(3.329)$ \\
Time fixed effects & $(1.108)$ & $(0.996)$ & $(4.600)$ & Yes \\
\hline Observations & No & Yes & Yes & Yes \\
$R^{2}$ & No & Yes & Yes & 2189 \\
\hline
\end{tabular}

Notes: Post.Treatment is our difference-in-differences estimator. Standard errors are in parentheses and clustered at the regional level. ${ }^{*} \mathrm{p}<0.10,{ }^{* *} \mathrm{p}<0.05,{ }^{* * *} \mathrm{p}<0.01$.

Table 2. Perceptions of energy security during the heatwave 


\begin{tabular}{lcccc}
\hline & $(1)$ & $(2)$ & $(3)$ & $(4)$ \\
\hline Post.Treatment & 2.728 & $3.518^{*}$ & 2.753 & 2.730 \\
Age & $(1.931)$ & $(1.829)$ & $(1.767)$ & $(1.787)$ \\
& & & -0.0661 & -0.0500 \\
Income & & $(0.462)$ & $(0.413)$ \\
& & $0.625^{*}$ & $0.619^{*}$ \\
Gender & & $(0.339)$ & $(0.336)$ \\
& & & 2.799 & 2.834 \\
Education & & $(1.861)$ & $(1.771)$ \\
& & & $5.013^{* * *}$ & $5.012^{* * *}$ \\
Environmental Regulation & & & $(0.571)$ & $(0.568)$ \\
& & & & 0.00456 \\
Constant & & & $40.80^{* * *}$ & $(0.030)$ \\
& & & $(4.361)$ & $40.49^{* * *}$ \\
Region fixed effects & $\left(1.66^{* * *}\right.$ & $60.64^{* * *}$ & Yes & Yes \\
Time fixed effects & No & $(1.008)$ & Yes & Yes \\
\hline Observations & No & Yes & 2189 & 2189 \\
$R^{2}$ & 2434 & 2434 & 0.080 & 0.080 \\
\hline
\end{tabular}

Note: Post.Treatment is our difference-in-differences estimator. Standard errors are in parentheses and clustered at the regional level. ${ }^{*} \mathrm{p}<0.10,{ }^{* *} \mathrm{p}<0.05,{ }^{* * *} \mathrm{p}<0.01$.

Table 3. Stated energy consumption behaviour during the heatwave 


\begin{tabular}{lccc}
\hline & $(1)$ & $(2)$ & $(3)$ \\
\hline Post.Treatment & -0.165 & -0.285 & -0.165 \\
Age & $(1.473)$ & $(1.449)$ & $(1.473)$ \\
& 0.0907 & 0.0200 & 0.0907 \\
Income & $(0.163)$ & $(0.114)$ & $(0.163)$ \\
& 0.249 & 0.198 & 0.249 \\
Gender & $(0.291)$ & $(0.297)$ & $(0.291)$ \\
& 0.645 & 0.734 & 0.645 \\
Education & $(0.886)$ & $(0.807)$ & $(0.886)$ \\
& $2.073^{* * *}$ & $2.086^{* * *}$ & $2.073^{* * *}$ \\
Environmental Regulation & $(0.418)$ & $(0.428)$ & $(0.418)$ \\
& $0.0580^{* * *}$ & $0.0579^{* * *}$ & $0.0580^{* * *}$ \\
Pro-environmental behaviour (Energy) & $(0.015)$ & $(0.015)$ & $(0.015)$ \\
& $0.446^{* * *}$ & $0.444^{* * *}$ & $0.446^{* * *}$ \\
Constant & $(0.013)$ & $(0.013)$ & $(0.013)$ \\
& $18.10^{* * *}$ & $21.51^{* * *}$ & $22.94^{* * *}$ \\
Region fixed effects & $(4.257)$ & $(1.924)$ & $(4.329)$ \\
Day fixed effects & Yes & Yes & Yes \\
Wave fixed effects & Yes & No & Yes \\
\hline Observations & No & Yes & Yes \\
$R^{2}$ & 4311 & 4311 & 4311 \\
\hline
\end{tabular}

Note: Post.Treatment is our difference-in-differences estimator. The number of observations pre-treatment is 3001 and the number of observations post-treatment is 1310. Standard errors are in parentheses and clustered at the regional level. ${ }^{*} \mathrm{p}<0.10,{ }^{* *} \mathrm{p}<0.05$, ${ }^{* * *} \mathrm{p}<0.01$.

Table 4. Perceptions of energy security after the heatwave.

\section{FIGURES}

Figure 1. Average maximum daily temperatures. Average maximum daily temperatures for treatment (red line) and control (blue line) regions. The shaded area represents our sample period of 15 to 25 July. Error bars denote standard error of the mean.

Data source: Met Office (2018). 


\section{METHODS}

\section{Data}

Individual-level data were collected through a survey instrument enumerated by an established research company (ResearchNow) over two periods: 18 to 25 July 2018 (Wave 1) and 3 to 14 December 2018 (Wave 2). The company's UK panel contains over 350,000 respondents varying widely by age, gender, education and income. To obtain a nationally representative sample, a quota-sampling strategy was used for the survey period as a whole. This approach set quotas for age, gender, education, income and regional distribution of the population to match UK characteristics. The NUTS1 regional grouping was used to classify respondents by region. In addition to demographic and other questions, the questionnaire included six statements relating to water, energy and food. Three statements were designed to capture stated perceptions of water, energy and food security and three statements were designed to capture stated proenvironmental behaviours. Respondents were asked to assign a value to each statement along a 100-point scale. A value of 0 indicated that the respondent strongly disagreed with the statement. A value of 50 indicated that the respondent neither agreed nor disagreed. A value of 100 indicated that the respondent strongly agreed with the statement. The survey questionnaire also included data on a number of control variables, including respondent age, gender, education, income, environmental preferences and stance toward environmental regulation. Survey questionnaires were time stamped allowing for the day during which the respondent undertook the survey to be identified.

Daily maximum temperature data from 1988 to 2018 were obtained from the UK Met Office’s Areal dataset. The Areal dataset is based on $1 \mathrm{~km}$ grid-point datasets derived from climate station data and averaged at the ITV regional level. To assign daily maximum temperatures to individual respondents, we overlayed the Areal dataset with the NUTS1 regional groupings and calculated weighted spatial averages. For example, the NUTS1 region South West overlaps with four ITV regions: Central (7.6\% overlap), Meridian (12.5\% overlap), HTV West (34.1\% overlap, West County (45.8\% overlap). We calculated the daily maximum temperature as a weighted geographic average of maximum temperatures according to the proportion of overlap (27). A full data glossary is presented in Supplementary Table 21.

\section{Data analysis}

The partial nature of the UK heatwave over the study period leaves us with treated and nontreated groups of individuals. This enables us to estimate a difference-in-differences regression of the form:

$$
\rho_{i, t, s}=\alpha_{0}+\beta \Phi_{i, t, s}+\zeta\left(d_{i, t}^{\text {post }} \cdot d_{i, s}^{\text {treat }}\right)+\omega_{i, t}+\varphi_{i, s}+\varepsilon_{i, t, s}
$$

where $\rho_{i, t, s}$ denotes perceptions of future water, energy, and food security, and proenvironmental behavior (on a scale from 0 to 100), for individual $i$, at time $t$, in region $s . \Phi_{i, t, s}$ represents a vector of characteristics (age, income, gender, education, and preferences) of individual respondent $i$, at time $t$, in region $s$. The coefficient $\zeta$ of the interaction term 
$\left(d_{i, t}^{\text {post }} \cdot d_{i, s}^{\text {treat }}\right)$ measures the treatment effect (or the difference-in-differences estimator). This captures the impact of the extreme temperatures, measuring the change in perceptions and environmental motivated behaviour of those exposed to extreme temperatures relative to the control group who were not exposed to extreme temperatures. Importantly this enables us to separate out the effect of other potential factors that influence changed perceptions and proenvironmental behaviour, including national media coverage. We estimate the above equation using time (day) fixed effects $\omega_{i, t}$ and region fixed effects $\varphi_{i, s}$ for individual respondent $i$. We estimate our difference-in-differences model using standard errors clustered at the regional level.

The two-wave difference-in-differences estimation follows the same format as above. However, in this case, we have two time periods: Wave 1 (18 to 25 July) and Wave 2 (3 to 14 December). We define the treatment group as those who live in regions that experienced extreme weather during our first sample period (that is, East of England, East Midlands, London, South East, West Midlands, and Yorkshire and the Humber). Those who live in the other regions are defined as the control group. In terms of time, we have the heatwave period (Wave 1) and the nonheatwave period (Wave 2). The key variable of interest is $\left(d_{i, t}^{\text {post }} \cdot d_{i, s}^{\text {treat }}\right)$, where it represents those in the treatment group from Wave 2. If the results from within Wave 1 persist, this estimator should be positive and significant. If they do not hold, the coefficient should be close to zero and insignificant.

\section{Robustness checks}

\section{$\underline{\text { Balance test }}$}

Supplementary Table 4 presents the results of our balance test between our control and treatment groups. As can be seen, the two groups are broadly similar. The two groups differ with respect to age, and to a lesser extent income. Importantly, we control for these observable differences in our preferred estimations.

\section{Testing for common/parallel trends}

Supplementary Figures 6 - 11 present an overview of water, energy and food security perceptions and stated pro-environmental behaviour over the survey period. In addition to providing a visualization of perceptions over the survey period, Supplementary Figures 6 - 11 are useful for investigating whether the common trends assumption between the control and treatment group holds. Starting first with perceptions of water, energy and food security, Supplementary Figures 6-8 show that perceptions tend to trend closely together pre-treatment. This is particularly stark for perceptions of energy security, where perceptions trend closely before clearly diverging in the post-treatment period. Similarly, Supplementary Figures 10 and 11 show that pro-environmental behaviour tends to trend closely together pre-treatment with respect to water and food consumption. The only exception seems to be stated pro-environmental behaviour relating to energy consumption (Supplementary Figure 9).

In Supplementary Table 22 we provide output from a common trends/placebo test. This estimation takes the following form: 


$$
\rho_{i, t, s}=\alpha_{0}+\beta \Phi_{i, t, s}+\sum_{d=d 20}^{d 25} \zeta\left(d_{i, t}^{\text {day }} \cdot d_{i, s}^{\text {treat }}\right)+\omega_{i, t}+\varphi_{i, s}+\varepsilon_{i, t, s}
$$

As can be seen, this equation is equivalent to our main DID estimation, apart from the term $\sum_{d=d 20}^{d 25} \zeta\left(d_{i, t}^{\text {day }} \cdot d_{i, s}^{\text {treat }}\right)$. This term describes a series of six dummy variables that take the value of 1 for individuals from within the treatment group regions who were surveyed on a given day from the $20^{\text {th }}$ to the $25^{\text {th }}$ of July, and zero otherwise. Owing to the fact that most of the responses were collected on two days (see Supplementary Table 2); one before the heatwave (18 July with 622 observations) and one during the heatwave (23 July with 1089 observations), we choose 18 July as our pre-control basecase. As can be seen, and consistent with the parallel trends assumption, the day.treatment dummies are not-significant in the pre-period but are in the post period. Consistent with our main results, we also find $23^{\text {rd }}$ and $25^{\text {th }}$ of July to have positive and significant coefficients for energy security perceptions.

Estimation using wild cluster bootstrapped standard errors

Recognising that we have a small number of regions (11 regions) to cluster our standard errors, we also estimate our model using wild cluster bootstrapping (lower-bound) (28). To generate our wild cluster bootstrapped standard errors, we set the initial value of the random-number seed to 100 and specify 1000 iterations. We find our results to be robust to the calculation of standard errors using wild cluster bootstrapping.

\section{$\underline{\text { Estimation using an alternative measure of treatment }}$}

To account for the possibility that the same high temperature may have different effects depending on the region's average temperature (for instance, Scotland is on average cooler than southern England), we also employ an anomaly measure that defines extreme temperature as the maximum daily temperature being at least 2 standard deviations greater than the 30 -year mean value of maximum daily temperature $(29,30)$. Our anomaly measure defines extreme temperatures using the following formula:

$$
T_{s, t}=\frac{X_{s, t}-\mu_{s}}{\sigma_{s}}
$$

where $T_{s, t}$ indicates extreme temperatures in region $s$ on day $t, X_{s, t}$ represents the maximum temperature for region $s$ on day $t$ and $\mu_{s}$ represents the long-term mean maximum temperature in July for region $s$ over the period 1988 to 2018. $\sigma_{s}$ is the standard deviation of the maximum temperature in July in region $s$ over the period 1988 to 2018. We define extreme temperatures as occurring when a region experiences a temperature that is at least 2 standard deviations greater than the long-term mean maximum temperature. The same 6 treatment regions experienced temperatures that were at least 2 standard deviations higher than the long-term mean value of 
maximum daily temperature. However, the day regions first experienced extreme temperatures varied (see Supplementary Figure 12).

Ethical approval and consent: Ethical approval was granted by the Departmental Research Ethics Committee Chair (Director of Research) under due process and all survey participants are drawn from ResearchNow’s panel using their processes for establishing informed consent.

\section{References}

27. Larcom, S., She, P-W. \& van Gevelt, T. Replication files for: The UK summer heatwave of 2018 and public concern over energy security. Figshare.

http://dx.doi.org/10.6084/m9.figshare.7482614 (2019).

28. A. Cameron., J. Gelbach, D. Miller, Bootstrap-based improvements for inference with clustered errors. The Review of Economics and Statistics 90, 414-427 (2008).

29. I. Salehyan, C. Hendrix, Climate shocks and political violence. Global Environmental Change 28, 239-250.

30. H. Randell, C. Gray, Climate variability and educational attainment: evidence from rural Ethiopia. Global Environmental Change 41, 111-123 (2016). 